\title{
CAROTID ATHEROSCLEROSIS ASSESSMENT USING ULTRASONOGRAPHY - MAKING IT AN EASY AND VALUABLE TOOL FOR THE GENERAL PRACTITIONER
}

\author{
Raluca Popa ${ }^{1}$, Cristina Stănescu², Dan Stănescư ${ }^{3}$, Adriana Gurghean ${ }^{4}$ \\ ${ }^{1}$ Dr. Professor Dimitrie Gerota Emergency Hospital \\ ${ }^{2}$ Colentina Clinical Hospital \\ ${ }^{3}$ Fundeni Clinical Institute \\ ${ }^{4}$ Coltea Clinical Hospital
}

\begin{abstract}
The thromboembolism of an asymptomatic carotid artery stenosis (CAS) causes stroke in 1015\% cases and in Europe, stroke causes more than 1 million deaths a year. This important cause of mortality may be evaluated by duplex ultrasound (DUS).

In five decades of experience, carotid DUS has proven to be a risk-free procedure, being widely available, easy to use, inexpensive, painless and quite reproducible.

The purpose of this article was to try to extend the usual indications of DUS assessment of carotid atherosclerosis (CA) in order to offer a tool for less experienced ultrasonographers to gather useful information for optimizing patient's management. We tried to review the literature and to provide a simple, easy to apply algorithm for estimating the presence and severity ofCA.
\end{abstract}

Keywords: carotid ultrasound, carotid screening algorithm, carotid atherosclerosis.

\section{Rezumat}

Tromboembolismul la nivelul unei stenoze carotidiene asimptomatice (SCA) cauzează accident vascular cerebral în 10-15\% dintre cazuri, iar în Europa accidentul vascular cerebral provoacă anual mai mult de 1 milion de decese. Această cauză importantă de mortalitate poate fi evaluată prin ultrasonografia duplex (DUS).

Pe parcursul a cinci decenii de experiență, ultrasonografia duplex carotidiană s-a dovedit o procedură fără riscuri, disponibilă pe scară largă, ușor de utilizat, necostisitoare, nedureroasă și destul de reproductibilă.

Scopul acestui articol a fost să încerce extinderea indicațiilor curente de evaluare prin DUS a aterosclerozei carotidiene (AC) pentru a le oferi praticienilor mai puțin experimentați în ultrasonografie un instrument pentru colectarea de informații utile pentru optimizarea managementului pacientului. Am încercat să analizăm literatura de specialitate și să oferim un algoritm simplu și ușor de aplicat pentru estimarea prezenței și severității AC.

Cuvinte cheie: ecografie carotidiană, algoritm de screening carotidian, ateroscleroză carotidiană. 


\section{INTERNAL}

\section{General Reviews}

\section{Introduction}

Stroke causes 1.1 million deaths annually in Europe, making it the second commonest cause of death ${ }^{(1)}$. About $10-15 \%$ of all strokes follow thromboembolism from a previously asymptomatic internal carotid artery (ICA) stenosis $>50 \%{ }^{(2)}$. Duplex ultrasound (DUS) is usually the first-line imaging modality because of its low cost and accessibility.

Mostly neurologist and vascular surgeons were interested so far in the assessment of carotid atherosclerosis (CA). But it was shown that up to two-thirds of asymptomatic patients with $C A$ have also subclinical coronary artery disease (CAD) $)^{(3)}$.

Using DUS, the prevalence of asymptomatic moderate $(>50 \%)$ and severe $(>70 \%)$ carotid stenosis in a population of 23.706 people (mean age 61 years, $46 \%$ male) was $2.0 \%$ and $0.5 \%$ respectively, which was not considered a reliable argument to make screening costeffective or clinically effective ${ }^{(4)}$.

Nevertheless, screening for asymptomatic carotid artery stenosis (CAS) could enable risk factor detection and best medical treatment (BMT) for screened patients (irrespective of stenosis severity or whether they undergo invasive revascularization procedures) and this could contribute in preventing myocardial infarction and cardiac deaths, which are more common than late stroke ${ }^{(5)}$.
A systematic review and meta-analysis including 17 studies reported late mortality in 11.391 patients with a CAS $>50 \%$. Overall, 5 year mortality was $24 \%$ (95\% Cl 20.5-26.8). Two-thirds of late deaths were the result of heart disease. Accordingly, risk factor modification and implementation of BMT in patients with screen-detected CAS could significantly reduce cardiac morbidity and mortality ${ }^{(6)}$.

DUS enable us to quantify the atherosclerotic burden in carotid arteries, more accessible compared to other vascular areas. A correlation between the presence of CA and atherosclerosis in other less accessible areas, such as the coronary arteries, was demonstrated $^{(7)}$. The purpose of this article was to try to extend the usual indications of DUS assessment of CA and also to involve more specialists in this process, for a better understanding of the patient's atherosclerotic burden, in order to optimize their management. The accuracy of DUS relies heavily upon the expertise of the ultrasonographer. Our intention is to provide a guideline for less experienced ultrasonographer providing a simple algorithm for estimating the presence and severity of CA.

\section{Indication of carotid Doppler ultrasound}

Besides evaluation of the patients having a cervical bruit or neurologic symptoms, 


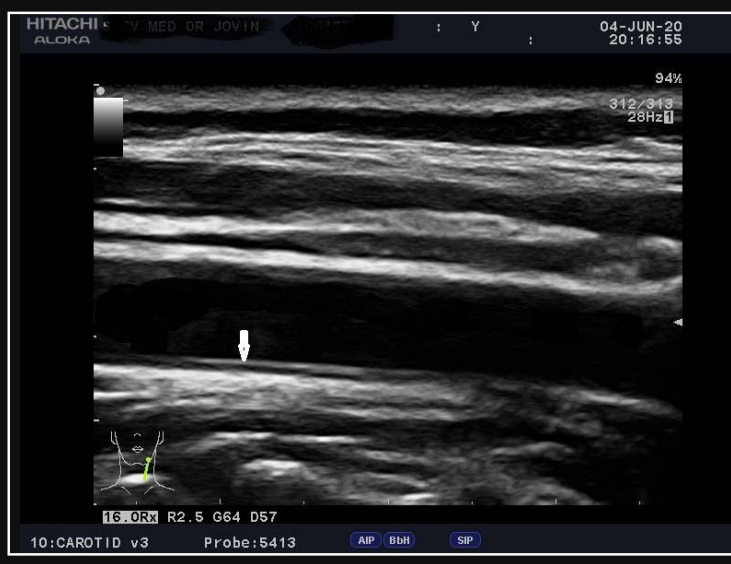

Figure 1. The three layers of intima-media complex (arrow); IMT represents the thickness of intima and media layer combined

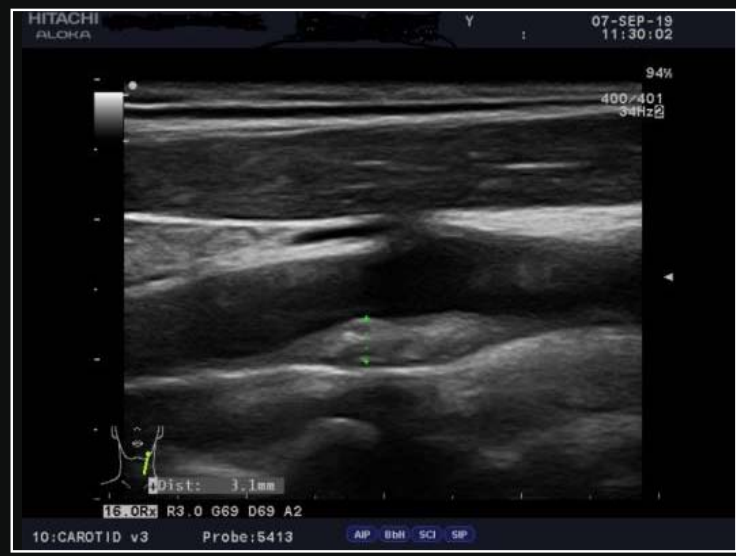

Figure 2. An echogenic heterogenous plaque

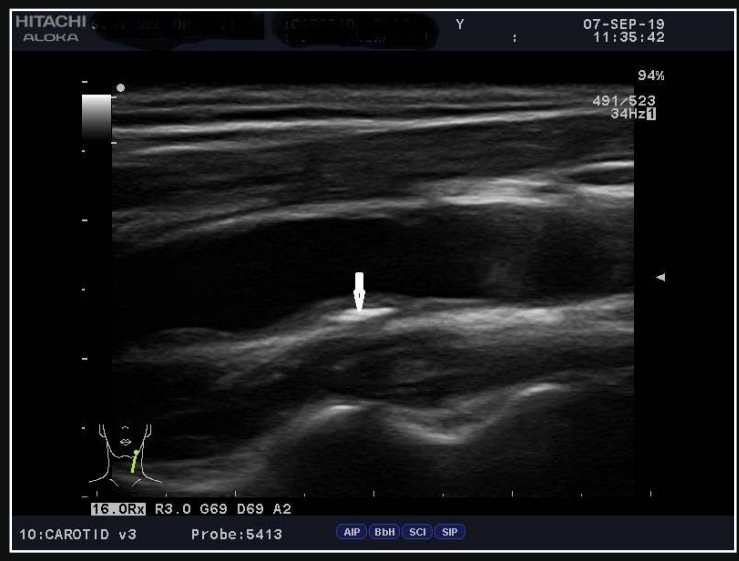

Figure 3. An echogenic heterogenous plaque with small calcium accumulation (arrow)

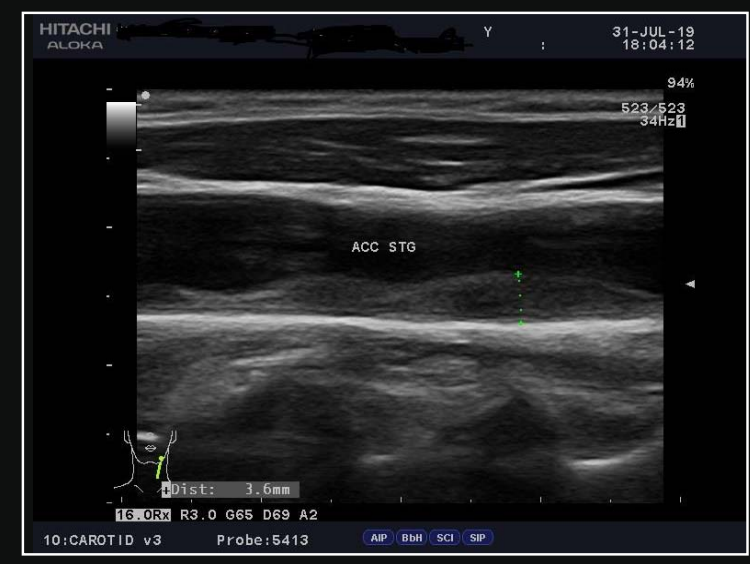

Figure 4. Hypoechoic plaque with smooth and regular surface

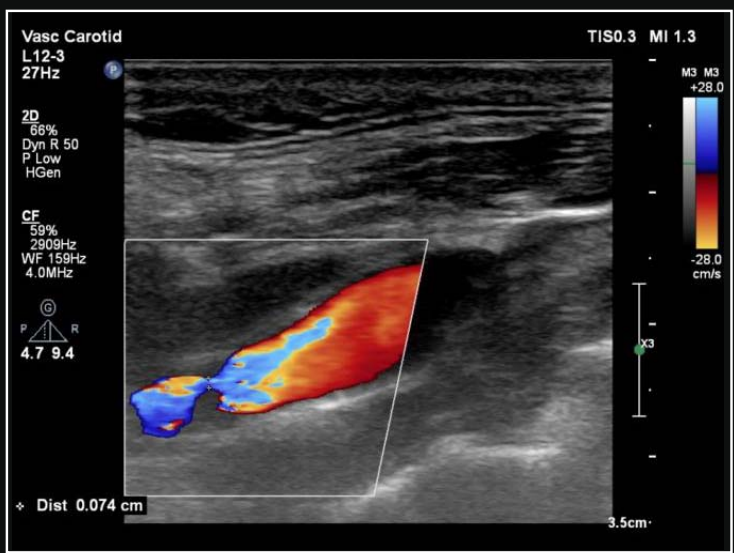

Figure 5. Localization of a stenosis by color Doppler

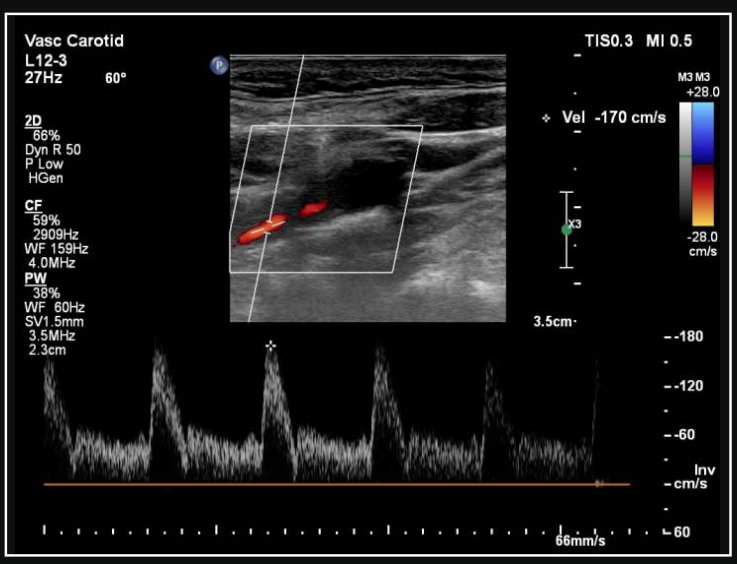

Figure 6. Pulsed wave Doppler is used to determine peak systolic velocity in a ICA stenosis 


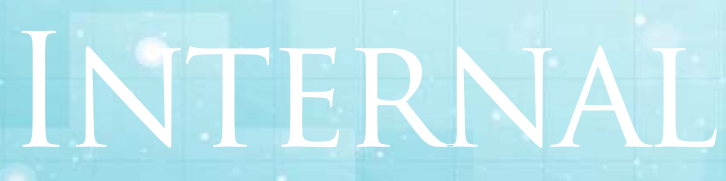

\section{General Reviews}

noninvasive imaging of the carotid arteries is indicated in discovering subclinical atherosclerosis. Due to the risk of intra- or postoperative neurologic complications after major cardiovascular surgical procedures, DUS is indicated in preoperative evaluation. Therefore the ultrasound examination can sometimes replace the angiography of the carotid arteries.

Other indications for DUS comprises: patients with seizures, drop attack or dizziness, high risk patients with atherosclerosis with other localization (coronary arteries, limb arteries), vasculopathies, Takayasu disease, fibromuscular dysplasia, pulsatile neck masses ${ }^{(8)}$.

These indications could be extended for instance in patients with arterial hypertension, for assessing subclinical hypertensionmediated organ damage, which could help stratify risk and change patient management ${ }^{(9)}$.

\section{Examination technique}

\section{Patient Position}

There are two possibilities for the patient positioning. The overhead position, used mainly by neurologists and lateral sitting position, which is more popular. A pillow or a rolled-up towel under the neck can improve the exposure.

The optimal patient head position is rotated 45 degrees away from the examined artery, with a relaxed neck. Multifrequency linear transducers are preferable: high frequency (7-12 MHz) for the distal two thirds of the common carotid artery (CCA) and bifurcation and lower frequency $(5 \mathrm{MHz})$ for the origin of the ICA and distal ICA ${ }^{(10)}$.

The first step in the examination sequence is a complete survey of the carotid arteries with B-mode and color flow imaging in transverse and longitudinal plans. The second step is examination of the interest area using pulsed Doppler in longitudinal plan.

\section{Carotid Anatomy and Imaging the Common, Internal and External Carotid Arteries}

The three carotid arteries should be examined bilaterally. The following parameters are to be identified: origin, caliber, wall structure and blood flow pattern. The branches of CCA should be differentiated. The ICA is located lateral and posterior to the ECA and is usually larger than ECA. The ECA has branches and ICA does not.

The Doppler spectrums are different, those from the ICA showing a lower resistive pattern and those from ECA - a higher resistive pattern, meaning that the velocity difference between systolic and diastolic phase of the ICA is smaller than that of the ECA ${ }^{(10)}$. There are some differences between the right and the left side. The CCA arises from the innominate artery on the right side and from the aortic arch on the left. 


\section{Pacient position:}

- Examining physician in lateral sitting position

- Patient supine, than turn the head 45 degrees, away from the examined artery

- Relaxed sternocleidomastoidian muscle

Transverse plan:

- Find CCA lateral to thyroid and medial to jugular vein

- Slide transducer cranial to th bifurcation - find ECA medial, ICA lateral (on the right side ICA lateral and posterior)

\section{Identifing the arteries:}

- In the distal wall

\section{Measuring IMT:}

- From the upper bright line (which is included) to the lower brigt line (which is not included)

\section{Plaques identification and characteristics:}

a. Thickness $>1.5 \mathrm{~mm}$

b. Localisation

c. Structure (ecodense, echolucent, calcified)

d. Contour (regular, irregular)

B mode - detecting atheroma plaques

\section{Stenosis:}

Pulsed Doppler in longitudinal plan (with correction angle of 60 degrees)

- Velocities - measured at the site of stenosis and proximal to the site

- Velocity ratio:

$\rightarrow \mathrm{vICA} / \mathrm{vCCA}>2 \rightarrow$ significant stenosis

$\rightarrow$ vICA/vCCA $>4 \rightarrow$ severe stenosis

Figure 7. Practical algorithm for estimating the presence and severity of carotid atherosclerosis 


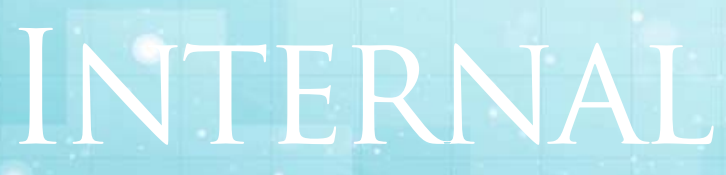

\section{General Reviews}

The proximal third is more profound, the distal two-thirds are more superficial. The ultrasound texture of the wall has three parallel layers and they form the intimamedia complex: the internal and the external are hyperechoic and the middle is hypoechoic (Figure 1).

The CCA has an average diameter of 6-7 mm and has no branches. The CCA divides into the ICA and the ECA at the superior border of the thyroid cartilage. The division point is slightly dilated and is known as carotid bulb. The ICA has $6.5-7.5 \mathrm{~mm}$ diameter at the carotid sinus and 3.5-5.5 $\mathrm{mm}$ beyond the bulb and also has no branches. The ECA has a lower diameter than ICA and is easily recognized by the presence of its branches ${ }^{(11)}$.

\section{Specifications of the Examination}

The CCA, its bifurcation, and both the ICA and ECA should be scanned in grayscale and with color Doppler in longitudinal and transverse planes. Color Doppler imaging should be used to detect stenosis, flow abnormalities, ECA branches and residual flow channels at the stenosis site.

Velocity measurements are obtained from long axis spectral Doppler for all vessels. Correction angle is essential for measuring blood flow velocity. The angle between the direction of the blood flow and the Doppler probe should be less than 60 degrees. To improve the accuracy of the measurement, the Doppler scale should be set to maximize the size of the waveforms ${ }^{(8)}$.

For each vessel evaluated, maximal peak systolic velocities and diastolic velocities, should be calculated. If significant stenosis is found, the maximum velocity should be recorded at the site of stenosis and proximal and distal to the site, and velocity ratios between ICA peak systolic velocity (PSV) at the level of stenosis and CCA PSV should be calculated.

\section{Interpretation}

Each ultrasound laboratory should have criteria used by all members of the staff, documented by literature and international guidelines $^{(8)}$. The report must contain a quantification of ICA stenosis upon velocity criteria and waveform analysis, should describe the waveforms - normal or abnormal, should characterize plaques, should indicate the vertebral artery flow direction, should describe any nonvascular abnormalities.

\section{Carotid intima-media thickness}

The intima - media thickness (IMT) has gained widespread use in the identification of atherosclerosis and consequently of the risk of developing vascular events like stroke or myocardial infarction ${ }^{(12)}$. The IMT represents the thickness of intima and media layer 


\begin{tabular}{|l|l|l|}
\hline$\%$ Stenosis (NASCET) & PSV ICA $(\mathrm{cm} / \mathrm{s})$ & PSV ICA/PSV CCA \\
\hline$<50 \%$ & $<125$ & $<2$ \\
\hline $50-69 \%$ & $125-230$ & $2-4$ \\
\hline $70-89 \%$ & $>230$ & $>4$ \\
\hline$>90 \%$ & $>400$ & \\
\hline
\end{tabular}

Table 1. Quantification of ICA stenosis ${ }^{(1)}$

Severity of internal carotid artery according to pulsed Doppler velocities. PSV=peak systolic velocity, ICA=internal carotid artery, CCA=common carotid artery

combined. The normal values of the IMT are dependent on measurement technique, ethnicity, gender and age ${ }^{(13)}$. The IMT can be visualized and measured at high resolution in B-mode ultrasound with transducers that can detect spatial resolution up until $0.05 \mathrm{~mm}$ in axial plane and $0.2 \mathrm{~mm}$ in the lateral plane. Longitudinal sections of the carotid arteries are to be obtained and the best way to diminish the overestimation of the IMT is to align the carotid artery parallel with the probe surface ${ }^{(10)}$.

The arterial wall is aligned by two bright lines, the upper bright line delineates blood from the intima and the lower bright line the media layer from the adventitia of the vessel, the distance between the two bright lines represents the IMT. The measurement should take place in the distal common carotid artery at least $5 \mathrm{~mm}$ below the distal end of CCA and a $10-\mathrm{mm}$-in-length straight arterial segment is required. It is advisable to avoid the measureme

nt where a focal lesion is present ${ }^{(14)}$. Nowadays there is widespread use software's that provide automatic measurements. The normal value in connection to age ranges between 0.4 to $0.5 \mathrm{~mm}$ in the 30's and increases up to $0.6-0.7 \mathrm{~mm}$ in the $50 \mathrm{~s}^{\prime(15)}$. An IMT above $0.9 \mathrm{~mm}$ is considered the marker of asymptomatic organ damage and marks an increased risk of cardiovascular disease ${ }^{(14)}$. Usually the value above $1.5 \mathrm{~mm}$ is considered to be an atheroma plaque ${ }^{(16)}$.

\section{Plaque Characteristics}

For the last 20 years there have been numerous studies trying to stratify the risk of developing a cardiovascular event based not only on the degree of stenosis but also on the characteristic of the atheroma plaques ${ }^{(17)}$.

The current American Society of Echocardiography (ASE) guidelines suggest standard screening methods of carotid plaques $^{(16)}$.

A carotid plaque is defined as focal wall thickening of at least $50 \%$ greater than that of the surrounding vessel wall or an isolated region with an IMT>1.5 $\mathrm{mm}$. Due to the usual eccentric location of the plaques, a circumferential scan in anterior to posterior angles and in the near or far walls of the common carotid artery, carotid bulb, and internal carotid artery segments is required. Typically, these are the segments more susceptible to plaque formation.

The continuous screen of all angles diminishes the risk of missing small dimension plaques, especially those with uniform consistency located on the near wall 


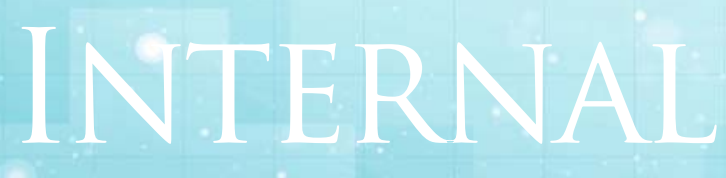

\section{General Reviews}

of the carotid bulb or internal carotid artery. Focal thickening can falsely appear when there is a change in the arterial diameter, such as at the level of the common carotid artery and carotid bulb and the images are not aligned perpendicular to the scan lines.

Ultrasound, examination, in B mode, should describe the echogenicity of the plaque, the surface and the presence of ulceration as some of these elements make the plaque more prone to rupture and consequently can lead to stroke. The consistency of the plaque is also described as either homogenous (uniform consistency) or heterogeneous (mixed consistency) often associated with irregular surface and ulceration. The echogenicity of the plaque is correlated with histological findings ${ }^{(18)}$.

The echogenic plaque includes a dense fibrous tissue and the increased echogenicity is related to the amount of collagen inside the plaque (Figure 2); calcium accumulation leads to high echoes in corresponding areas (Figure 3).

The isoechoic plaque refers to a signal of the plaque similar to the intima media complex $^{(10)}$. Echolucent/hypoechoic plaque comprises a thin fibrous cap covering a lipid core with a high content in macrophage cells and hemorrhage areas. Hypoechoic plaque is usually associated to symptomatic lesions that increase the risk of stroke. The surface of the plaque is described as smooth and regular, irregular or ulcerated (Figure 4). Ulceration is defined as a variation of contour height between 0.4 to $2 \mathrm{~mm}$. The emphasis on its detection is considered to be the hallmark in determining the vulnerability of atheroma plaque, the marker of a previous plaque rupture and a predictor of subsequent vascular events ${ }^{(19)}$.

The identification of plaque ulceration may suggest that the patients could be at risk of future ischemic events. There is however a lack of standardization of this measurement, moreover is has been shown that the accuracy of the method is inversely correlated with the degree of the stenosis. The measurement is also affected by an eventual malposition of the sonography probe that is not parallel to the vessel axis and by artifacts caused by the presence of calcifications which reflect the acoustic wave and can hide an ulceration (19). 3D ultrasonography seems to solve these issues as it can be used both for plaque characterization and monitoring. In preliminary studies the plaque volume measured on 3D ultrasound seems to be more sensitive than the IMT for the follow up of the treated atheroma plaques ${ }^{(20)}$.

The applications of an ultrasound enhancing agent (UEA) results in better definition of plaque anatomy, including vessel wall ulcerations (21,22) $^{2}$ and intra-plaque neovascularization ${ }^{(23,24)}$. 
The place of ultrasonography in carotid stenosis detection and quantification

Ultrasound examination in B- mode is useful in detecting anomalies of the vessel wall, its thickness and small atheroma plaques, becoming important in detecting focal lesions at this level.

Color Doppler ultrasonography shows the distribution of vascular flow, being useful also in identifying the type of the vessel and the localization of a stenosis (Figure 5). However, color Doppler is not helpful in quantifying a stenosis, but it is useful in delineating atheroma plaques that are hypoechogenic and differentiating between occlusion and critical stenosis. In advanced atheromatous disease, numerous artifacts can be generated, thus hemodynamic criteria become important.

A severe stenosis or occlusion modulates the up and downstream vascular parameters, as a consequence of a reduced flow volume, a drop in pressure and the formation of vascular collaterals. The pulsed wave Doppler is used to determine PSV, with angle correction between 45 to 60 degrees (Figure 6 ). The PSV is measured at the site of carotid stenosis, identified by color Doppler. A PSV above $125 \mathrm{~cm} / \mathrm{sec}$ lead to the suspicion of a stenosis of more than $50 \%$ and more than $70 \%$ when the value surpasses $230 \mathrm{~cm} / \mathrm{sec}^{(1)}$. The other direct parameter of quantification is the ratio between ICA PSV at the level of stenosis and CCA PSV (measured $3 \mathrm{~cm}$ below the bulb level) (9).

A ratio below 2.0 is normal or the grade of stenosis is inferior to $50 \%$, a ratio between 2.0-4.0 corresponds to a stenosis of 50 to $69 \%$ and a ratio above 4.0 to a stenosis of more than $70 \%{ }^{(1)}$. The use of the ratio is dependent on a normal common and external carotid artery (Table 1 ).
The degree of stenosis could be further quantified in $B$ mode in longitudinal section. Traditionally, the degree of stenosis in ICA has been measured by conventional digital subtraction angiography (DSA), by means of NASCET (North American Symptomatic Carotid Endarterectomy Trial) and ESCT (The European Carotid Surgery Trial) derived parameters ${ }^{(25)}$.

But longitudinal measurement may lead to a suboptimal evaluation of stenosis, therefore using cross sectional area reduction could be more appropriate. Although correlation between peak sistolic and end-diastolic ICA velocities and cross-sectional percent stenosis were demonstrated (26), no internationally accepted ultrasound criteria for describing the degree of stenosis were validated, except for velocity parameters ${ }^{(1)}$. We consider that for screening purposes, these are the most easy to obtain.

We propose the following algorithm, in five steps, for less experienced ultrasonographers, in order to extend the assessment of carotid atherosclerosis (Figure 7).

\section{Limitation of carotid Doppler ultrasound}

Limitations of the Doppler ultrasound examination are the acoustic shadowing from the calcified atheroma, which makes finding a proper sonic window for color and pulsed Doppler difficult.

Another limitation is the false elevation of the PSV with contralateral internal carotid artery occlusion or in tortuous vessel without stenosis $^{(11)}$.

Aknowledgment: This short paper was part of the preparation work for the Doctoral Thesis of the main author. This thesis is leaded by professor G.A. Dan, FESC, FAHA, FACC, FEHRA 


\section{References}

1. A.R.Naylor, J.-B. Ricco, G.J. de Borst. Management of Atherosclerotic Carotid and Vertebral Artery Disease: 2017 Clinical Practice Guidelines of the European Society for Vascular Surgery (ESVS), Eur J VascEndovascSurg (2018) 55, 3-81.

2. Naylor AR. Why is the management of asymptomatic carotid disease so controversial? The Surgeon 2015;13:34-43

3. B. Lopez-Melgar, L. Ferenandez-Friera, B. Oliva. Et al. Subclinical Atherosclerosis Burden by 3D Ultrasound in mid-life. The PESA Study. JACC 2017;70:301-313

4. de Weerd $M$, Greving JP, Hedblad B, Lorenz $M W$, Mathiesen EB, O'Leary $D H$, et al. Prediction of asymptomaticcarotid artery stenosis in the general population identificationof high-risk groups. Stroke 2014;45:2366-71

5. Giannoukas AD, Chabok M, Spanos K, Nicolaides $A$. Screening for asymptomatic carotid plaques with ultrasound. EurJ Vasc EndovascSurg 2016;52:309-12.

6. Giannopoulos A, Kakkos S, Abbott A, Naylor AR, Richards T,Mikhailidis $D P$, et al. Long-term mortality in patients withasymptomatic carotid stenosis: implications for statin therapy. -EurJ VascEndovascSurg2015; 50:573-82.

7. D. Migliorino, A. Mignano, S. Evola et al Correlation between carotid atherosclerosis and coronary artery disease: A retrospective study of 1067 patients, NMCD, Volume 27, Issue 1, Page e28, 2017, DOI: https://doi.org/10.1016/j.numecd.2016.11.077

8. AIUM Practice-Parameter Extracranial Cerebrovascular Ultrasound 2016, http://www. aium.org/ resources/guidelines, 2-8

9. B. Williams, G. Mancia, W. Spiering et al. 2018 ESC/ESH Guidelines for the management of arterial hypertension. European Heart Journal 2018;39:30213104

10. Whal Lee. General principles of carotid Doppler ultrasonography. Ultrasonography. 2014 Jan; 33(1): 1117 . Published online 2013 Dec 11. doi: 10.14366/usg.13018
11. Crisan S - Carotid UItrasound -Medical Ultrasonography 2011, Vol 13, no 4, 326-330

12. Jayanta Paul, Kishore Shaw, Somnath Dasgupta, and Mrinal Kanti Ghosh1 Measurement of intima media thickness of carotid artery by B-mode ultrasound in healthy people of India and Bangladesh, and relation of age and sex with carotid artery intima media thickness: An observational study. J Cardiovasc Dis Res. 2012 AprJun; 3(2): 128131.doi: 10.4103/0975-3583.95367

13. Stein JH, Douglas PS, Srinivasan SR, Bond MG, Tang $R, L i S$, et al. Distribution and cross-sectional age-related increases of carotid artery intima-media thickness in young adults: The Bogalusa Heart Study. Stroke. 2004;35:27827.

14. Simon A, GariepyJ, Chironi G, Megnien JL, Levenson J. Intima-media thickness: A new tool for diagnosis and treatment of cardiovascular risk. J Hypertens, 2002; 20:159-69

15. Iana Simova Intima media thickness; appropriate evaluation and proper measurement .e-Journal of Cardiology Practice vol 13, No21 -05 May 2015

16. A.M. Jjohri, V. Nambi, T.Z. Naqvi et al. Recommendations for the assessment of Carotid arterial Plaque by Ulrasound for the Characterisation of Atherosclerosis and Evaluation of cardiovascular Risk: from the American society of Echocardiography. J Am Soc Echocardiogr 2020;33:917-33

17. H.Sillesen.Carotid Intima-Media Thickness and/or Carotid Plaque: What is Relevant? European Journal of Vascular and Endovascular Surgery Published :April 28, 2014 DOI: Http://doi.org/10,1016/j.ejvs.2014.04.026

18. Roman Komorovsky and Alessandro Desideri Carotid Ultrasound Assessment of Patients with Coronary Artery Disease: A Useful Index for Risk Stratification. Vasc Health Risk Manag. 2005 Jun; 1(2): 131136. Published online 2005 Jun. doi: 10.2147/vhrm.1.2.131.64077

19. J. Yuan, A. Usman, T. Das, A.J. Patterson, J.H. Gillard and M.J. Graves Imaging Carotid Atherosclerosis Plaque Ulceration: Comparison of Advanced Imaging Modalities and Recent Developments American Journal of 
Neuroradiology April 2017, 38 (4) 664-671; DOI: https://doi.org/10.3174/ajnr.A5026

20. Makris GC, Lavida A, Griffin M, Geroulakos G, Nicolaides AN. Three dimensional ultrasound imaging for the evaluation of carotid atherosclerosis. Atherosclerosis. 2011;219:377383.

21. ten Kate GL, van Dijk AC, van den Oord SC, Hussain $B$, Verhagen HJ, Sijbrands EJ, et al. Usefulness of contrastenhanced ultrasound for detection of carotid plaque ulceration in patients with symptomatic carotid atherosclerosis. Am J Cardiol 2013;112:292-8.

22. van den Oord SC, Akkus Z, Renaud G, Bosch JG, van der Steen AF, Sijbrands EJ, et al. Assessment of carotid atherosclerosis, intraplaque neovascularization, and plaque ulceration using quantitative contrastenhanced ultrasound in asymptomatic patients with diabetes mellitus. Eur HeartJ Cardiovasc Imaging 2014;15:1213-8. 23. Mantella $L E$, Colledanchise $K N, H_{-}$etu $M-F$, Feinstein SB, Abunassar J, Johri AM. Carotid intraplaque neovascularization predicts coronary artery disease and cardiovascular events. Eur Heart J Cardiovasc Imaging 2019;20:1239-47.

24. Staub D, PatelMB, Tibrewala A, Ludden D, Johnson M, Espinosa $P$, et al. Vasa vasorum and plaque neovascularization on contrast-enhanced carotid ultrasound imaging correlates with cardiovascular disease and past cardiovascular events. Stroke 2010;41:41-7.

25. Staikov IN, Arnold M, Mattle HP, et al. Comparison of the ECST, CC, and NASCET grading methods and ultrasound for assessing carotid stenosis. European Carotid Surgery Trial. North American Symptomatic Carotid Endarterectomy Trial. I Neurol 2000; 247:681686.

26. G. Rodriguez, D. Arnaldi, C. Campus et al. Correlation between Doppler velocities and duplex ultrasound carotid Cross-sectional Percent Stenosis. Acad Radiol 2011;18;1485-1491 